\title{
Transversely Isotropic Creep Characteristics and Damage Mechanism of Layered Phyllite Under Uniaxial Compression Creep Test
}

Jiabing Zhang

Guangxi University

Xiaohu Zhang

Guangxi University

Zhen Huang ( $\nabla$ hzcslg@163.com )

Guangxi University

Helin Fu

Central South University

\section{Research Article}

Keywords: Layered phyllite, creep characteristics, damage mechanism, bedding angle, uniaxial compressive creep test

Posted Date: August 4th, 2021

DOl: https://doi.org/10.21203/rs.3.rs-673213/v1

License: (9) This work is licensed under a Creative Commons Attribution 4.0 International License.

Read Full License 


\title{
Transversely isotropic creep characteristics and damage mechanism of layered phyllite under uniaxial compression creep test
}

\author{
Jiabing Zhang ${ }^{1}$, Xiaohu Zhang ${ }^{2}$, Zhen Huang ${ }^{3}$, and Helin Fu ${ }^{4}$ \\ ${ }^{1}$ Assistant professor, College of Civil Engineering and Architecture, Guangxi University, Nanning 530004, \\ China (E-mail: zhang.j.b@gxu.edu.cn) \\ ${ }^{2}$ Postgraduate student, College of Civil Engineering and Architecture, Guangxi University, Nanning 530004, \\ China (E-mail: zhang_xh2020@163.com) \\ ${ }^{3}$ Assistant professor, College of Civil Engineering and Architecture, Guangxi University, Nanning 530004, \\ China (E-mail: hzcslg@163.com) (Corresponding author) \\ ${ }^{4}$ Professor, School of Civil Engineering, Central South University, Changsha 410075, China (E-mail: \\ fu.h.1@csu.edu.cn)
}

\begin{abstract}
The layered surrounding rocks of deep tunnels undergo large creep deformation due to the presence of planes of weakness and the presence of prolonged high in-situ stress, thereby the deformation severely endangers the safety of tunnels. This study conducts uniaxial compression creep tests to experimentally investigate the transversely isotropic creep characteristics and the damage mechanism of layered phyllite samples having bedding angles of $0^{\circ}, 22.5^{\circ}, 45^{\circ}, 67.5^{\circ}$, and $90^{\circ}$. The results indicate that the creep deformation of the specimens takes place in four stages: the instantaneous elastic deformation stage, the deceleration creep stage, the steady-state creep stage, and the accelerated creep stage. The cumulative creep deformation and the creep time during the steady-state creep stage of the specimens initially decrease and then increase as the bedding angle changes from $0^{\circ}$ to $90^{\circ}$, thereby, corresponding to the initial increase and subsequent decrease in creep rate during the deceleration creep stage. Based on the existing viscoelastic-plastic damage creep model, the creep parameters $E_{1}, E_{2}, \eta_{2}$, and $\eta_{3}$ are observed to initially decrease and then increase with the increase in bedding angle, hence demonstrating that the creep characteristics and damage mechanism of the layered rock mass are controlled by the effect of the natural weakness planes and show significant transversely isotropic characteristics.
\end{abstract}

Keywords Layered phyllite; creep characteristics; damage mechanism; bedding angle; uniaxial compressive creep test

\section{Introduction}

With the continued advancement of "the Belt and Road" project and the comprehensive launch of the 
Sichuan-Tibet railway project in China, the execution of deep rock mass engineering projects has become increasingly common. The long-term safety of such engineering projects is primarily controlled by the rock mass creep characteristics, and the influence of rock mass creep characteristics gets more pronounced in layered rock masses (Chen et al. 2019). The previous studies have shown that the creep characteristics of layered surrounding rocks of deep tunnels deteriorate significantly due to the presence of natural weakness planes and of the long-term high in-situ stress, which may lead to large deformations and subsequent failure of structures (Fu et al. 2018; Chen et al. 2019; Xu et al. 2020) (as shown in Fig. 1). Therefore, it is essential to examine the transversely isotropic creep characteristics and the damage mechanism of layered rock masses to enhance the long-term stability and safety of deep rock mass engineering structures.

a)
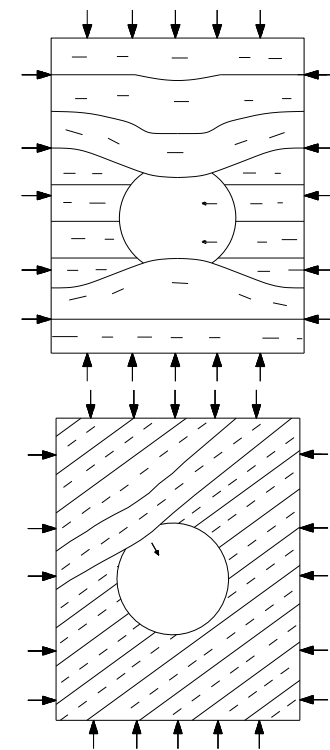

b)

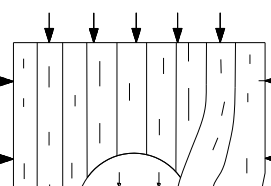

c)

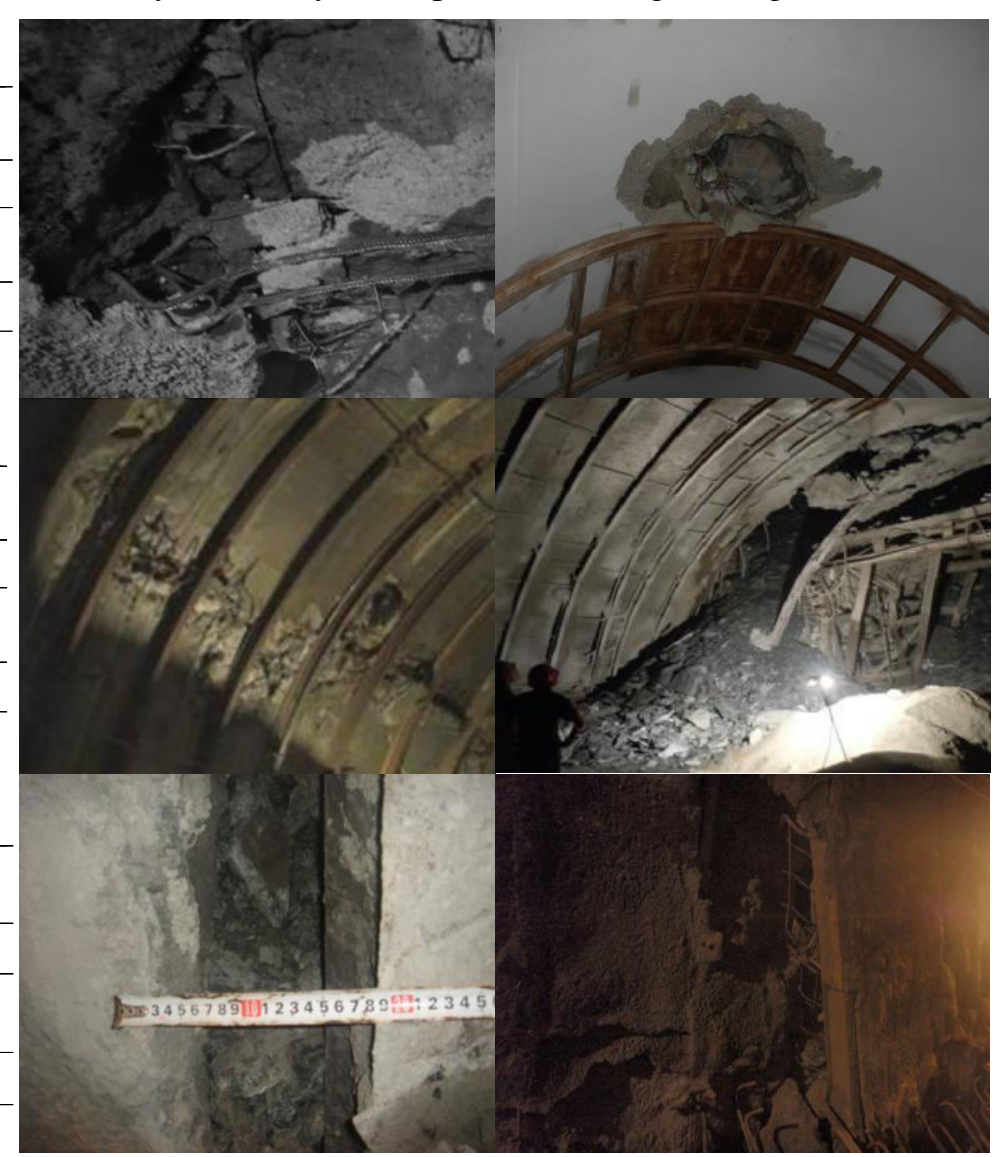

Fig. 1 Large deformation failure characteristics of layered surrounding rock in a tunnel. a) bedding angle of $0^{\circ}-30^{\circ}$; b) bedding angle of $30^{\circ}-75^{\circ}$; c) bedding angle of $75^{\circ}-90^{\circ}$.

Considerable efforts have been made to investigate the strength and the deformation characteristics of layered rock masses using the uniaxial and triaxial compression tests and the shear tests (Tien et al. 2006; Lee et al. 2015; Hu et al. 2017; Zhang et al. 2019; Shen et al. 2021; Yang et al. 2021). A detailed understanding of the effect of the orientations of the bedding plane on the mechanical properties of layered rock masses has been established. For studying the creep characteristics of rock masses, Xie et al. (2011) 
conducted a series of hydrostatic and triaxial compression tests on chemically degraded samples and reported the influence of ionic concentration and $\mathrm{pH}$ of aqueous solutions on the creep characteristics of limestone. Nadimi et al. (2011) studied the rheological characteristics and long-term strength of surrounding rock containing deeply buried tunnels by triaxial compression creep tests. The results show that the internal structure of the surrounding rock is constantly adjusted and reorganized due to the presence of prolonged high in-situ stress, continuously developing the creep deformation of the surrounding rock and decreasing the bearing capacity. Chen et al. (2017) investigated the effect of temperature and stress on the creep characteristics of Beishan granite. They found that the peak strength and peak strain of rock initially increases and then decreases with increasing temperature. Moreover, Hadiseh et al. (2018); Reza Taheri et al. (2020); Wang et al. (2021), and many others have studied the creep characteristics of rock masses through multi-step and mono-step creep tests. In addition, the creep damage mechanism of rock masses has been extensively studied by various researchers, and some creep constitutive models have been developed (e.g., Zhao et al. 2009; Zhou et al. 2011; Yang et al. 2015; Li et al. 2017; Wu et al. 2020). These studies primarily focused on the creep characteristics and damage mechanism of isotropic rocks; however, there is still a lack of systematic understanding of transversely isotropic creep characteristics and the damage mechanism of layered rock masses considering the weakening effect of macroscopic bedding planes, which needs to be further supplemented and improved.

In this paper, a series of uniaxial compression creep tests were conducted on layered phyllite samples having different bedding angles to obtain the creep curve and the creep rate curve. The effect of the angle of bedding plane at each creep stage and the damage mechanism of the evolution of creep failure morphology of the layered phyllites had been discussed in detail. Finally, the variation of rock creep parameters with the change in bedding angles was determined based on the existing viscoelastic-plastic damage creep model, which provides a reference for further understanding the transverse isotropic creep damage mechanism of the layered rock mass.

\section{Test materials and experimental procedures}

\subsection{Sample preparation}

In this experiment, few representative phyllite rock blocks were collected from a typical supporting project site. The layered phyllite samples had a height of $100 \mathrm{~mm}$ and a diameter of $50 \mathrm{~mm}$, which is in strict accordance with the International Society for Rock Mechanics ISMR (ISMR, 2007). It was ensured that the error in the sample preparation process does not exceed $0.3 \mathrm{~mm}$, and the non-parallelism at both 
ends remains lower than $0.05 \mathrm{~mm}$. Five sets of a total fifteen drill cores were drilled out from the phyllite blocks; each set containing three samples having an angle of $0^{\circ}, 22.5^{\circ}, 45^{\circ}, 67.5^{\circ}$, and $90^{\circ}$ between the loading direction and the bedding surface (as shown in Fig. 2). After processing, the samples with higher integrity were selected for acoustic measurement, and the samples with greater homogeneity were further screened for testing by measuring the wave speed of the samples. Among the three samples of each bedding angle, two were selected for the conventional uniaxial compression test and one for the uniaxial compression creep test.

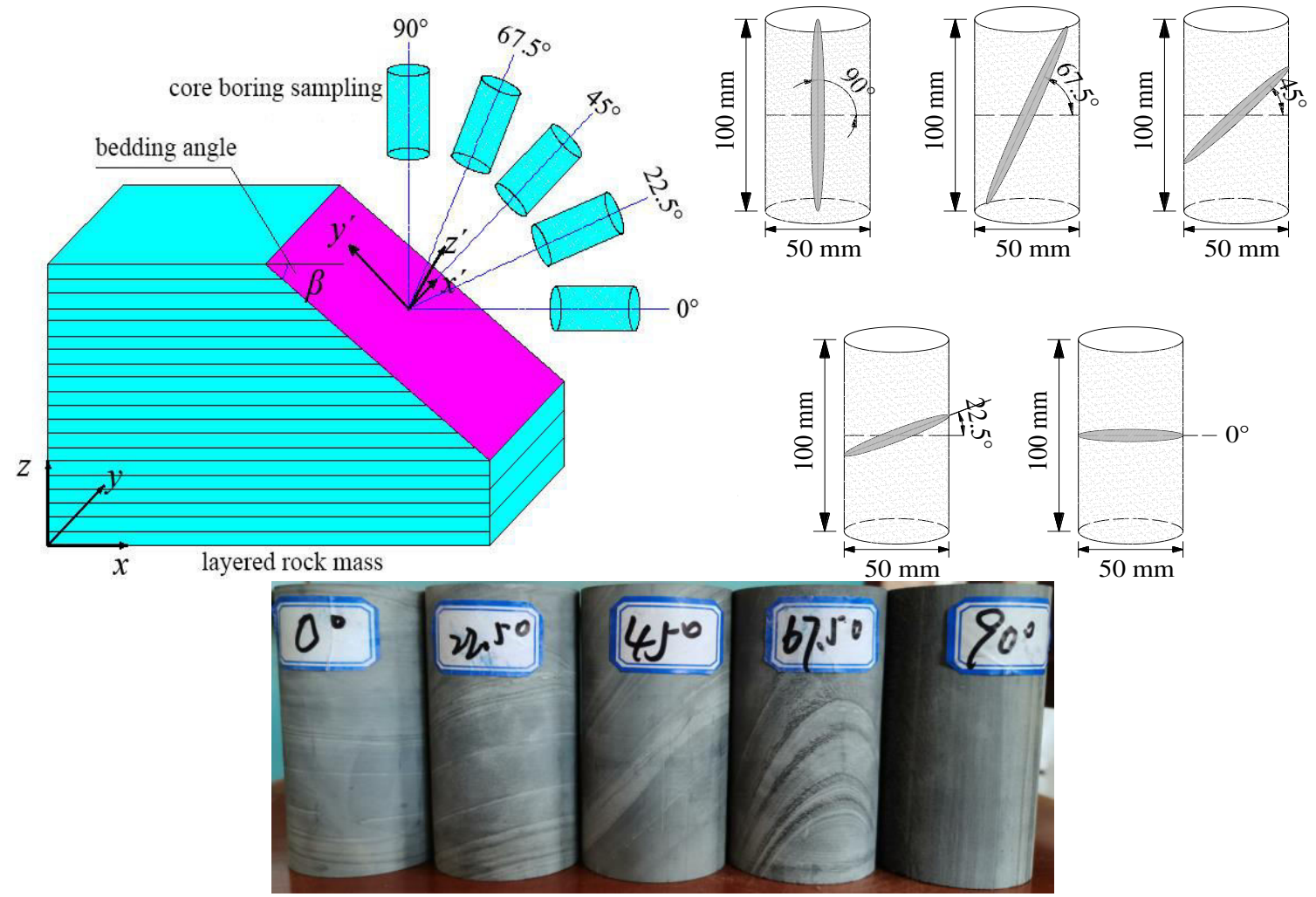

Fig. 2 Schematic diagram of sample preparation.

\subsection{Experimental procedures}

The conventional uniaxial compression test and uniaxial compression creep test were performed using the RMT-301 rock and concrete mechanics testing machine (as shown in Fig. 3). The maximum test force of the equipment is $1500 \mathrm{kN}$; the accuracy is $\pm 0.5 \%$; the deformation rate range is 0.0001 to $1 \mathrm{~mm} / \mathrm{s}$; and the loading rate range is $0.01-90 \mathrm{kN} / \mathrm{s}$. In the uniaxial compression test, displacement is used to control the loading, the loading rate is $0.005 \mathrm{~mm} / \mathrm{s}$, and the axial deformation of the sample is measured using a linear variable differential transducer (LVDT). The uniaxial peak strength of a rock sample at a given angle to bedding $\sigma_{c}$ is the average value of the uniaxial peak strength of the rock sample under the same bedding angle. The uniaxial compression creep test was conducted using stress-controlled loading at a loading rate of $0.01 \mathrm{MPa} / \mathrm{s}$. After each load level was added to the predetermined value and was kept stable for 48 
hours, ensuring that the displacement rate of the rock sample after 48 hours was less than $0.01 \mathrm{~mm} / \mathrm{h}$, the next loading level was applied in a step-wise fashion until the sample failed (as shown in Fig. 4). A high-speed camera was used to record the entire deformational process and the failure of rock samples. The failure strength, failure mode, and fragmentation distribution characteristics for each bedding direction were analyzed.

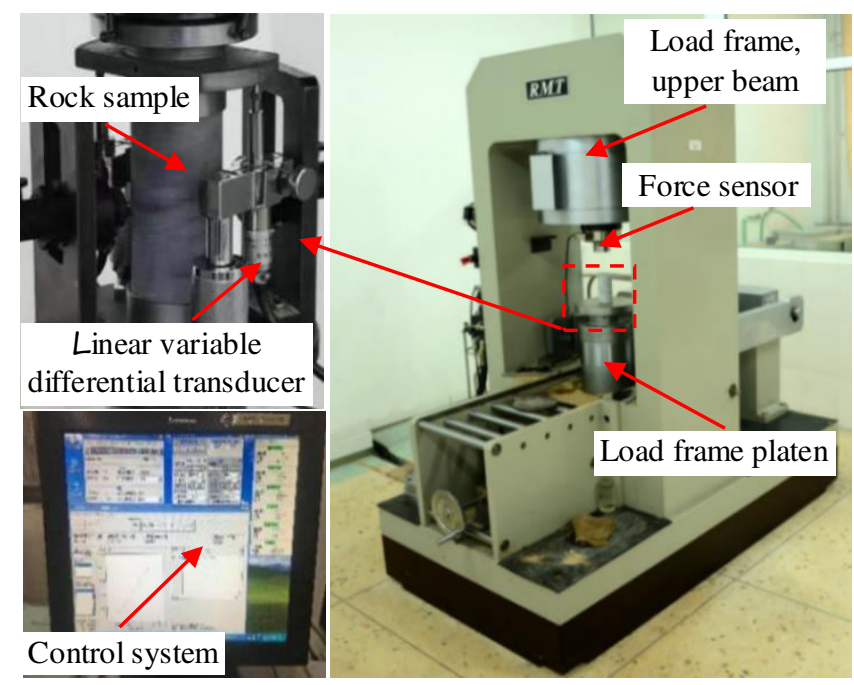

Fig. 3 Equipment used in the uniaxial compression creep tests.

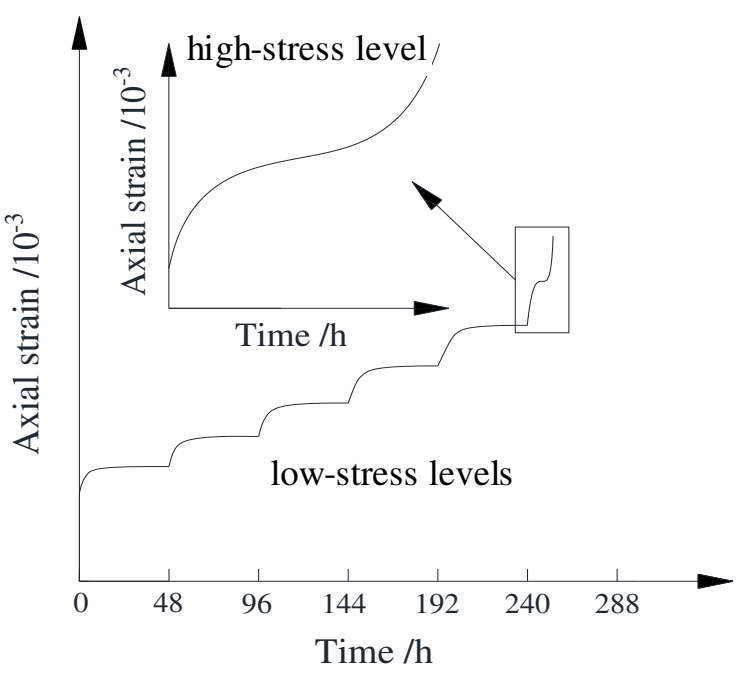

Fig. 4 Loading time control schematic diagram for each uniaxial compression creep test.

\section{Test results and analysis}

\subsection{Uniaxial compression test results and analysis}

Fig. 5 shows the stress-strain relationship curves of two sets of rock samples having different bedding angles. The stress-strain curves of rock samples having different bedding angles are similar and can be divided into four stages: the compaction stage, the linear elastic stage, the plastic yielding stage, and the failure stage. The relationships between the bedding angle and the uniaxial compressive strength and peak strain of layered phyllite are illustrated in Fig. 6. Notably, the bedding angle has a significant influence on the uniaxial compressive strength and peak strain of layered phyllite, and the uniaxial compressive strength and peak strain of layered phyllite initially decrease and then increase as the bedding angle changes from $0^{\circ}$ to $90^{\circ}$, forming a U-shaped curve. The change trend is similar to the test results of phyllite from Xu et al. (2018). When the bedding angle is $90^{\circ}$, the uniaxial compressive strength of the rock sample is the largest, and the average compressive strength is $141.80 \mathrm{MPa}$. When the bedding angle is $22.5^{\circ}$, the uniaxial compressive strength of the rock sample is the smallest, and the average compressive strength is 50.28 MPa. It is concluded that the rock samples used in the test have little dispersion, which is helpful for further exploring the creep characteristics of layered phyllite. 

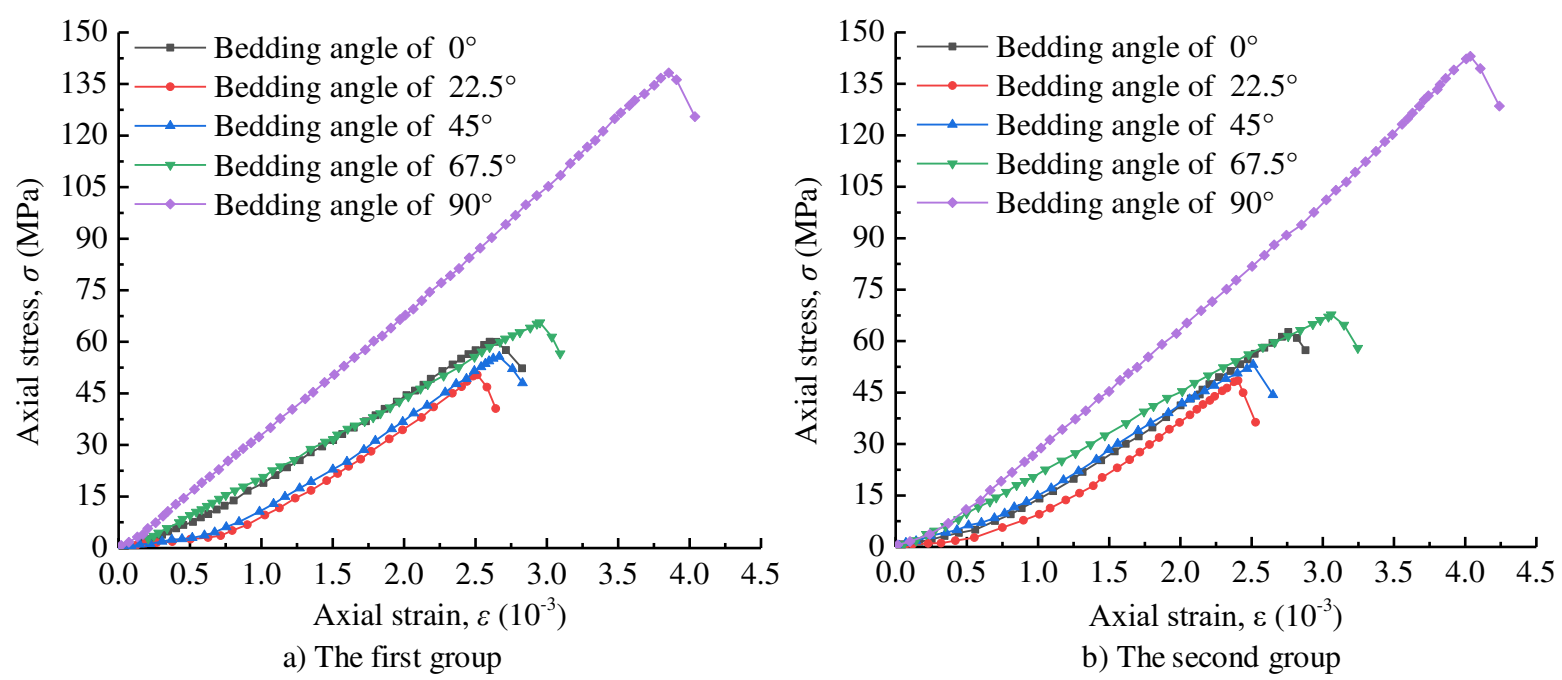

Fig. 5 Stress-strain relationship curves of layered phyllite under uniaxial compression.

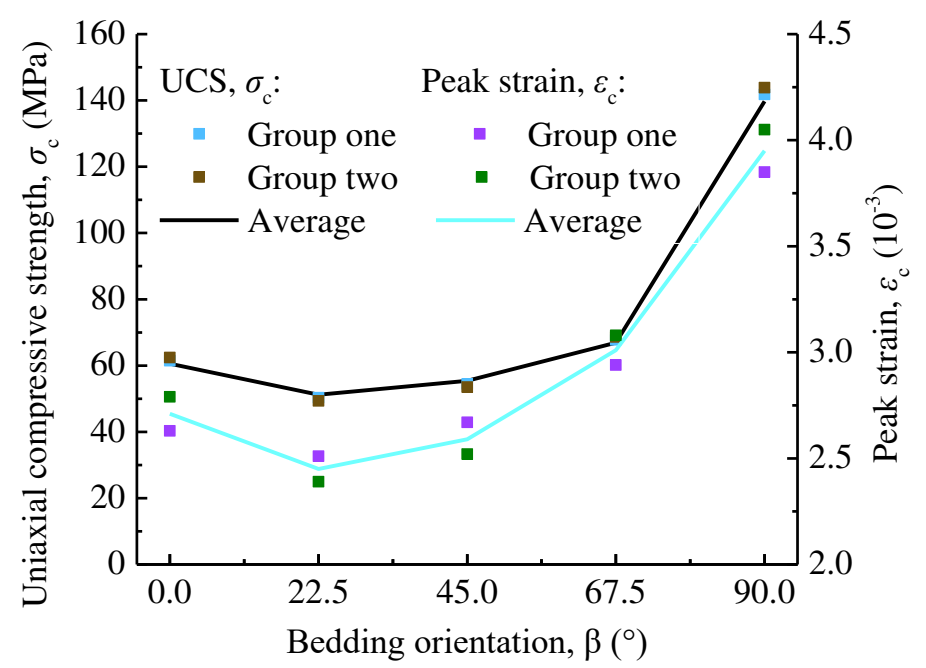

Fig. 6 Relationships between the bedding angle and the uniaxial compressive strength and peak strain of layered phyllite.

\subsection{Uniaxial compression creep test results and analysis}

The uniaxial compression creep test was conducted using the graded incremental loading method, and the axial loading was divided into 6 loading levels from low-stress level to high-stress level according to the long-term rock strength $\sigma_{s}$ (the long-term rock strength takes $75 \%$ of the uniaxial peak strength $\sigma_{c}$ of the rock sample). It is assumed that the first 5 loading levels are low-stress levels $\sigma_{m}\left(\sigma_{m}<\sigma_{s}\right)$, and the last loading level is a high-stress level $\sigma_{n}\left(\sigma_{n}>\sigma_{s}\right)$. For example, the long-term strength of a rock sample with a bedding angle of $90^{\circ}$ is $106.35 \mathrm{MPa}$. The loading level of the rock sample was divided into 6 levels $(86,91$, 96, 101, 106, and $111 \mathrm{MPa})$, the rock is at a low-stress level when the first 5 loading levels $(86,91,96,101$, and $106 \mathrm{MPa}$ ) are applied, and the rock is at a high-stress level when the last loading level (111 MPa) is applied. The uniaxial compression creep test schemes of rock samples having bedding angles of $0^{\circ}, 22.5^{\circ}$, $45^{\circ}, 67.5^{\circ}$, and $90^{\circ}$ are listed in Table 1. 
Table 1 Load scheme of uniaxial compression creep test.

\begin{tabular}{ccccccccc}
\hline Bedding & Uniaxial peak & Long-term rock & \multicolumn{5}{c}{ Stress levels of various loading levels (MPa) } \\
\cline { 4 - 8 } angle, $\beta\left(^{\circ}\right)$ & strength, $\sigma_{c}(\mathrm{MPa})$ & strength, $\sigma_{s}(\mathrm{MPa})$ & 1 & 2 & 3 & 4 & 5 & 6 \\
\hline 0 & 61.49 & 46.12 & 25 & 30 & 35 & 40 & 45 & 50 \\
22.5 & 50.28 & 37.71 & 20 & 24 & 28 & 32 & 36 & 40 \\
45 & 54.48 & 40.86 & 24 & 28 & 32 & 36 & 40 & 44 \\
67.5 & 67.76 & 50.82 & 29 & 34 & 39 & 44 & 49 & 54 \\
90 & 141.80 & 106.35 & 86 & 91 & 96 & 101 & 106 & 111 \\
\hline
\end{tabular}

The strain-time relationship curves of layered phyllite samples under various loading levels are presented in Fig. 7. The following conclusions can be drawn:

(1) When the axial stress on the rock sample is at the first four stress levels, the rock sample first undergoes instantaneous elastic deformation after each level of load is applied and then enters the deceleration creep stage. The creep rate gradually decreases with increasing time, at which point the slope of the creep curve becomes approximately 0 , and the creep tends to be in the steady-state creep stage. Because the loading stress at this stage is less than the long-term strength of the rock, the particles inside the rock are not destroyed, but the internal pores and cracks are gradually compressed and they ultimately close, which leads to an increase in the directional flow resistance inside the rock as well as a gradual increase in rock creep.

(2) When the axial stress on the rock sample is at the fifth stress level, the rock will enter the steady-state creep stage after a short deceleration creep stage. The creep strain value of the rock in the steady-state creep stage has a linear relationship with time. Since the loading stress at this stage is close to the long-term rock strength; as the loading time increases, the rock sample develops shear cracks along the bedding direction. Cracks within the rock sample continue to develop; however, the failure does not occur.

(3) When the axial stress on the rock sample is at the last stress level, the stable creep rate accelerates and quickly enters the accelerated creep stage. In this stage, the rock creep rate increases rapidly with time, and the development of non-linear accelerating creep occurs, which finally reaches the ultimate compressive strain and leads to the failure of rock sample.

(4) When the axial stress on the rock sample is less than the long-term strength of the specimens, the creep strain of the rock mass is composed of three parts: the instantaneous elastic deformation stage, the deceleration creep stage, and the steady-state creep stage. When the axial stress on the rock sample is greater than the long-term strength of the specimens, the creep strain of rock mass is composed of the instantaneous elastic deformation stage, the deceleration creep stage, the steady-state creep stage, and the 
accelerated creep stage.

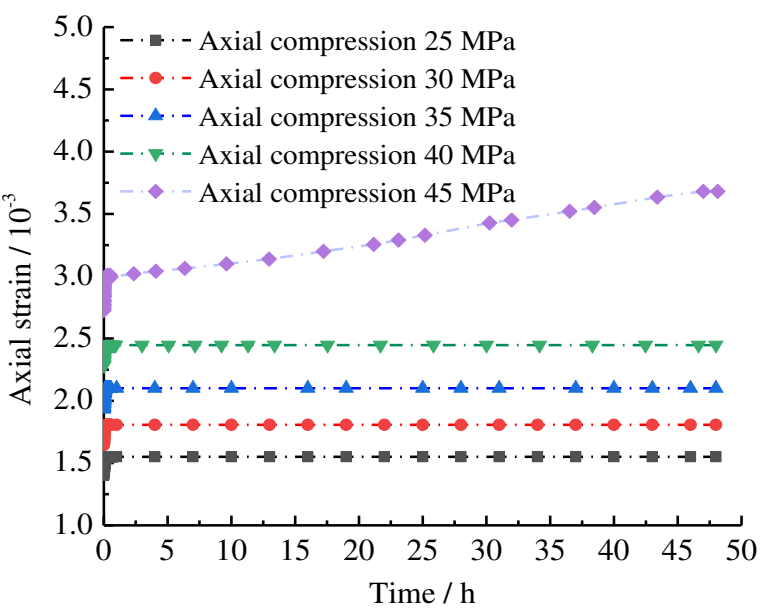

a) Bedding angle of $0^{\circ}$

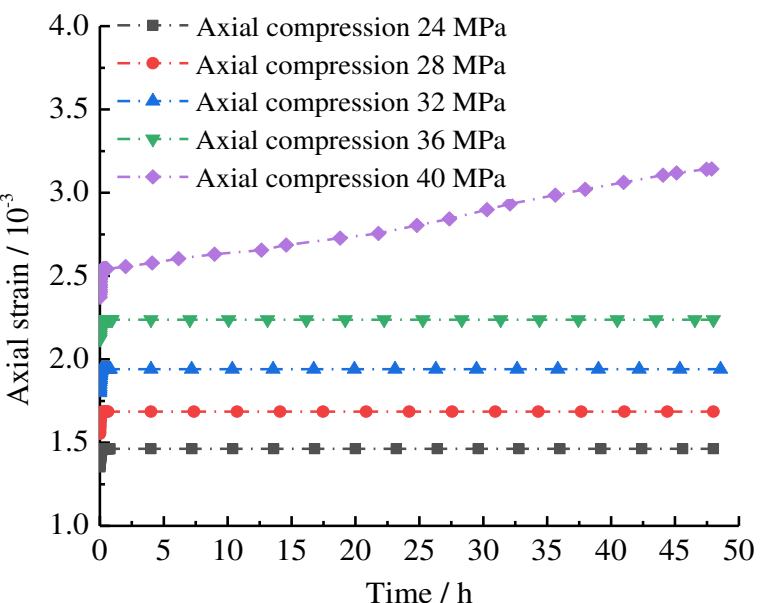

c) Bedding angle of $45^{\circ}$

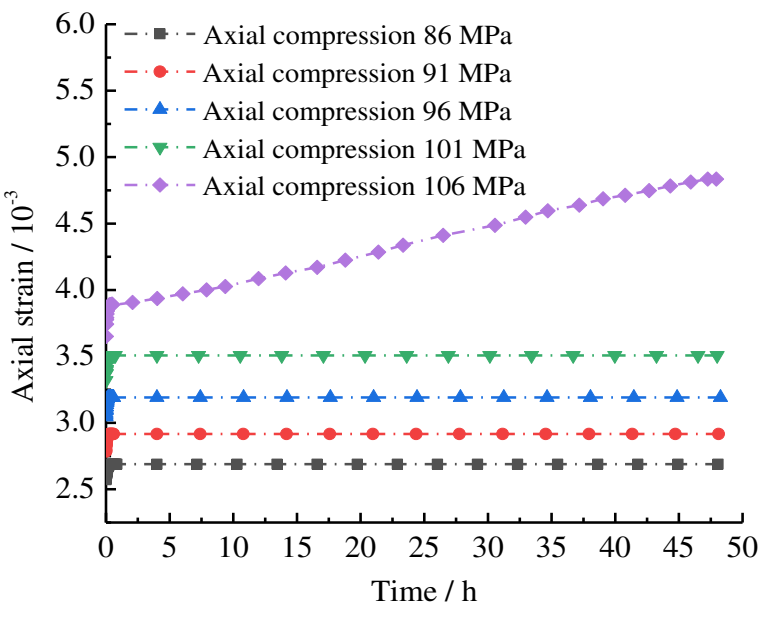

e) Bedding angle of $90^{\circ}$

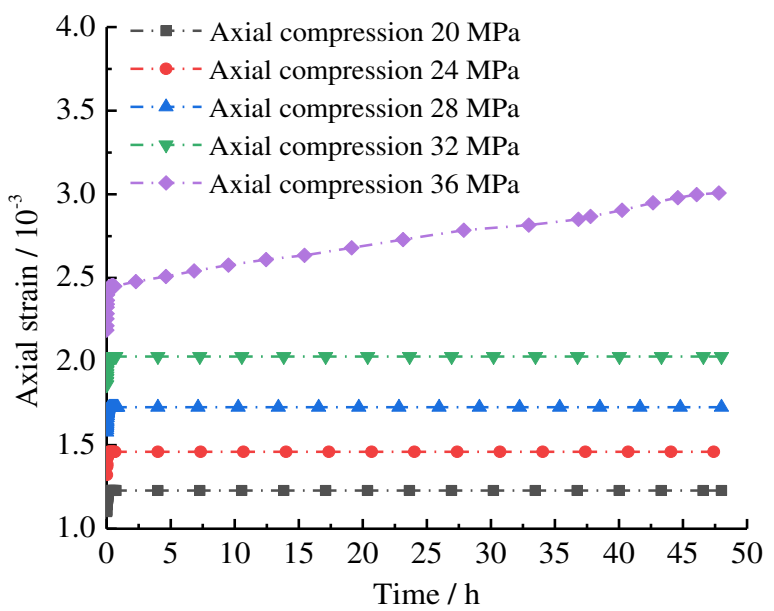

b) Bedding angle of $22.5^{\circ}$



d) Bedding angle of $67.5^{\circ}$

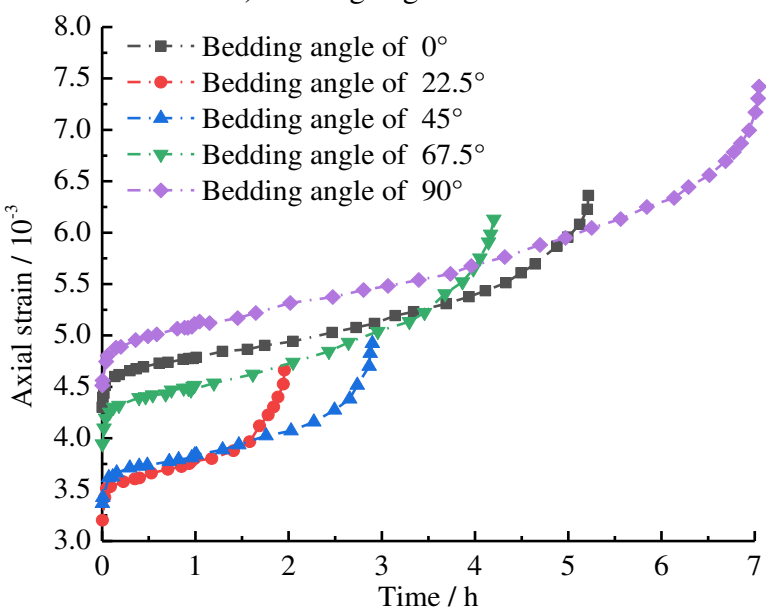

f) The last-stage loading

Fig. 7 Creep curves of layered phyllite samples under various loading conditions. a) the first five-stage loading creep curve of the rock sample with a bedding angle of $0^{\circ}$; b) the first five-stage loading creep curve of the rock sample with a bedding

angle of $22.5^{\circ} ; \mathrm{c}$ ) the first five-stage loading creep curve of the rock sample with a bedding angle of $45^{\circ}$; d) the first five-stage loading creep curve of the rock sample with a bedding angle of $67.5^{\circ}$; e) the first five-stage loading creep curve of the rock sample with a bedding angle of $90^{\circ}$; f) the last-stage loading creep curve of rock samples having bedding angles of $0^{\circ}, 22.5^{\circ}, 45^{\circ}, 67.5^{\circ}$, and $90^{\circ}$.

The strain-time relationship curves of layered phyllite samples under the last-stage loading are shown 
in Fig. $7 \mathrm{f}$. The creep time of the rock sample in the steady-state creep stage first decreases and then increases as the bedding angle changes from $0^{\circ}$ to $90^{\circ}$. It is primarily because of the reason that with the increase in bedding angle, the shear stress on the bedding surface first increases and then decreases, and the growth rate of shear cracks first accelerates and then decelerates.

Figs. 8 and 9 show the cumulative creep deformation curves and the creep rate curves of the deceleration creep stage of the specimens under various loading levels, respectively. For the same bedding angle, the cumulative creep deformation of the rock sample and the axial displacement rate of the deceleration creep stage both show concave growth roughly as the loading level increases. Under the same stress loading level, as the bedding angle changes from $0^{\circ}$ to $90^{\circ}$, the cumulative creep deformation of the rock sample and creep rate of the deceleration creep stage are different. When the bedding angle is $22.5^{\circ}$, the cumulative creep deformation of the rock sample is the smallest, and the creep rate corresponding to the deceleration creep stage is the largest. The effect of the bedding angle on the creep characteristics of layered phyllite is clearly visible under the high-stress loading level.

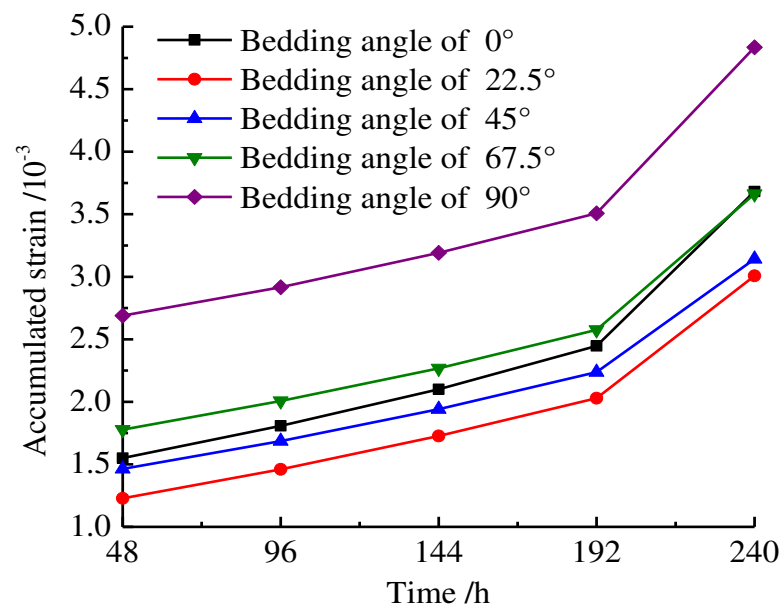

Fig. 8 Cumulative creep deformation curves of the specimens under various loading conditions.

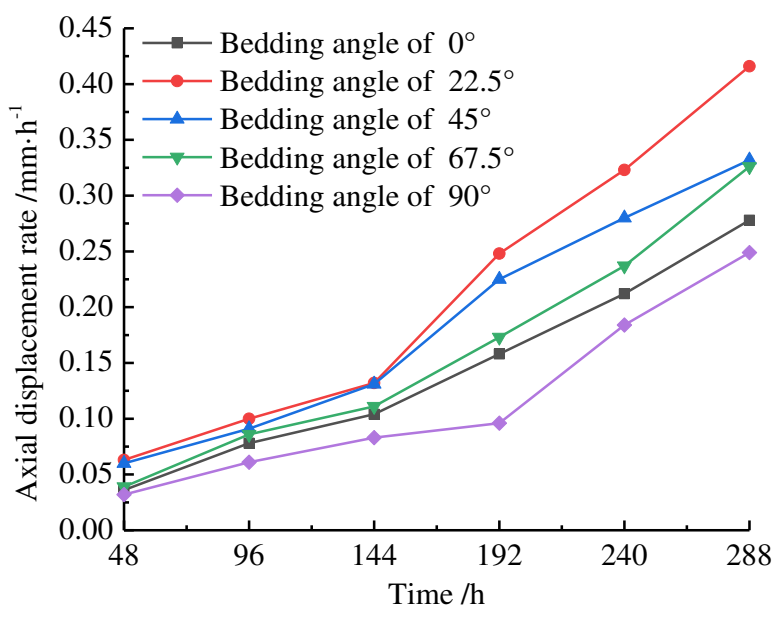

Fig. 9 Creep rate curves of the specimens during the deceleration creep stage under various loading conditions.

The typical failure characteristics of layered phyllite samples having different bedding angles under uniaxial compression creep test are presented in Fig. 10. When the bedding angle is $0^{\circ}$, the rock sample undergoes shear failure along a certain angle relative to the vertical axis, and the long-term strength of the rock is relatively high. When the bedding angle is $22.5^{\circ}-67.5^{\circ}$, because the bedding surface has a weakening effect on the rock sample, shear cracks along the bedding direction form near the bedding surface, causing the rock sample to undergo shear slip failure at the bedding surface. When the bedding angle is $90^{\circ}$, a typical vertical splitting failure occurs parallel to the bedding plane. 


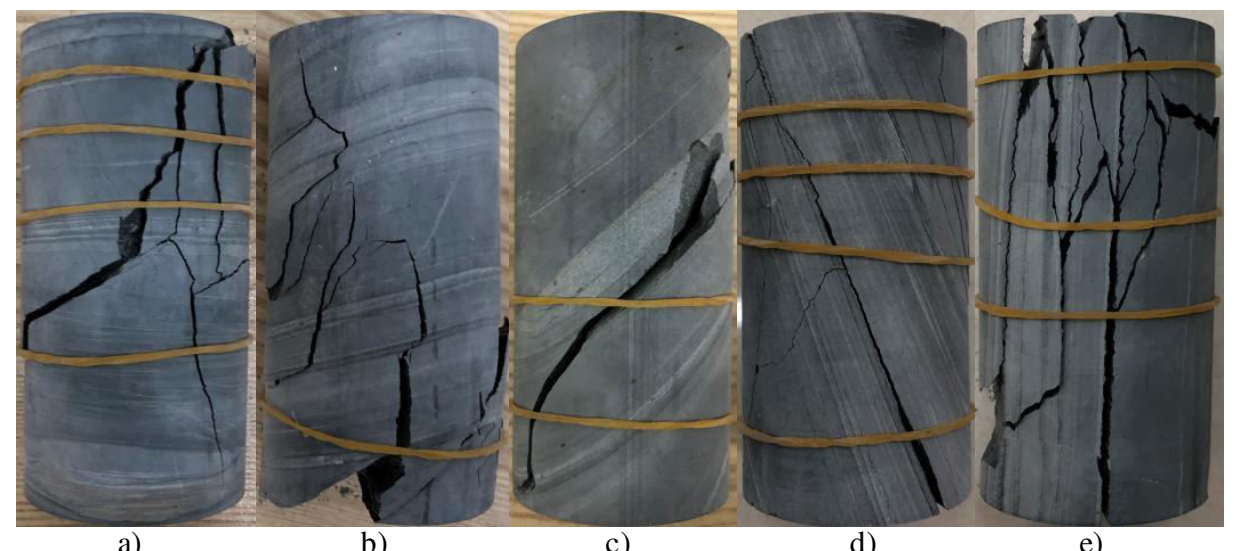

Fig. 10 Typical failure characteristics of layered phyllite samples under uniaxial compression creep for a: a) bedding angle of $0^{\circ}$; b) bedding angle of $22.5^{\circ}$; c) bedding of $45^{\circ}$; d) bedding angle of $67.5^{\circ}$; e) bedding angle of $90^{\circ}$.

\section{Transversely isotropic creep damage mechanism of the layered rock masses}

\subsection{Damage creep model of the layered rock masses}

To further explore the transversely isotropic creep damage mechanism of layered rock masses, a damage creep model that considers the weakening effect of bedding planes has been constructed based on the existing viscoelastic-plastic damage creep model, and the influence of bedding angle on the transversely isotropic creep damage mechanism of layered rock masses has been quantitatively discussed. The results of the laboratory uniaxial compression creep test of layered phyllite show the development of instantaneous strain in the rock sample in the initial loading stage. Since the loading time at this stage is shorter than the later creep time, the elastic strain is considered to be completed instantaneous at this stage, and its constitutive relations are described by elastomers. Then it enters the deceleration creep stage. When the level of the axial stress on the rock sample is small, the strain rate gradually decreases and tends towards 0 . The strain curve at this stage shows significant nonlinear characteristics, and its constitutive relationship can be described as a nonlinear Kelvin body. When the stress level of the creep test is close to the long-term rock strength, the rock strain has a linear relationship with time after the deceleration creep stage. The constitutive relationship at this stage can be described as a viscous body. When the stress level exceeds the long-term strength of the rock itself, the rock undergoes the deceleration and steady-state creep stage, and quickly enters the accelerated creep stage. At this time, the internal fissures within the rock sample continue to develop and gradually form macroscopic cracks. In this process, the creep damage increases sharply with time, resulting in failure of the rock sample (as shown in Fig. 11). 


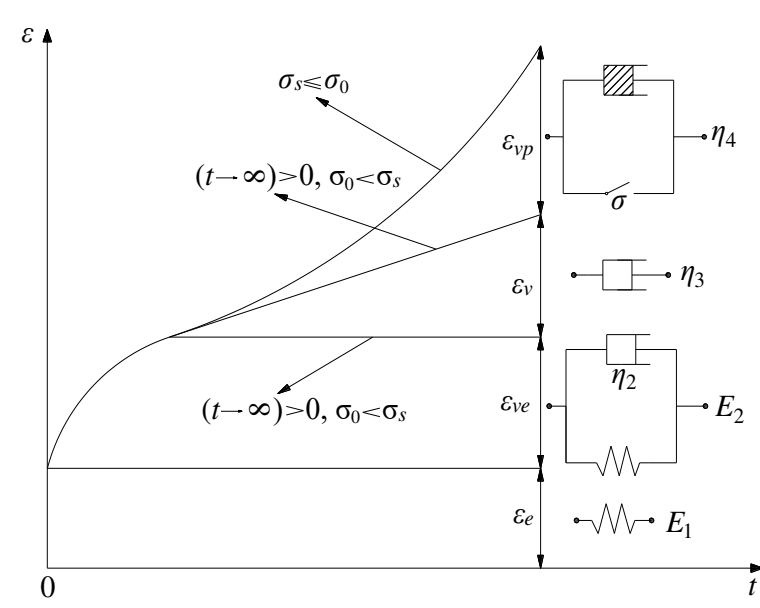

Fig. 11 Creep curves of layered rock masses.

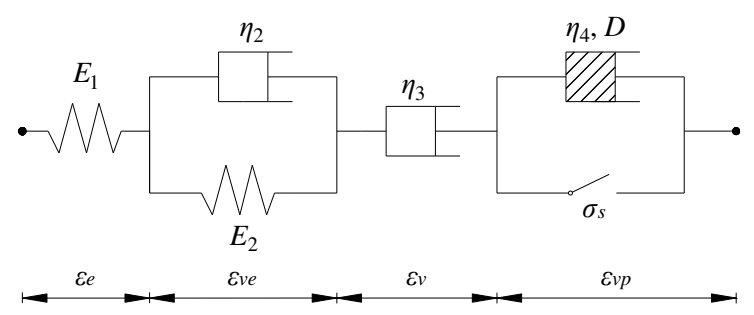

Fig. 12 Damage creep model of layered rock masses.

Based on the creep curves of layered rock masses under different stress levels, this study connects the following classical rock mechanics elements in a series: elastic body, nonlinear Kelvin body, viscous body, and damage viscoplastic body. By considering the non-stationarity component of the element parameters under the action of bedding surface weakening and aging damage, a damage creep model of the whole rock creep process considering the weakening effect of the macro-bedding surface and aging damage has been constructed (as shown in Fig. 12).

\subsection{One-dimensional equation of the damage creep model of the layered rock masses}

According to the model series and parallel stress-strain relationship:

$$
\left\{\begin{array}{l}
\sigma=\sigma_{e}=\sigma_{v e}=\sigma_{v}=\sigma_{v p} \\
\varepsilon=\varepsilon_{e}+\varepsilon_{v e}+\varepsilon_{v}+\varepsilon_{v p}
\end{array}\right.
$$

where $\varepsilon$ is the total strain; $\varepsilon_{e}, \varepsilon_{v e}, \varepsilon_{v}$, and $\varepsilon_{v p}$ are the strain of the elastic body, nonlinear Kelvin body, viscous body, and damage viscoplastic body, respectively; $\sigma_{e}, \sigma_{v e}, \sigma_{v}$, and $\sigma_{v p}$ are the stress of the elastic body, nonlinear Kelvin body, viscous body, and damage viscoplastic body, respectively.

The one-dimensional equations of the elastic body, nonlinear Kelvin body, and viscous body are given as follows (Zhao et al. 2017; Liu et al. 2017):

$$
\begin{gathered}
\varepsilon_{e}=\frac{\sigma_{e}}{E_{1}}=\frac{\sigma}{E_{1}} \\
\varepsilon_{v e}=\frac{\sigma}{E_{2}}\left[1-\exp \left(-\frac{E_{2}}{\eta_{2}} t\right)\right] \\
\varepsilon_{v}=\frac{\sigma}{\eta_{3}} t
\end{gathered}
$$

where $E_{1}$ and $E_{2}$ are the elastic modulus of the elastic body and nonlinear Kelvin body, respectively; $\eta_{2}$ and $\eta_{3}$ are the viscosity coefficient of the nonlinear Kelvin body and viscous body, respectively.

The differential constitutive equation of the damage viscoplastic body by introducing the damage variable $D$ (Kachanvo 1992; Cao et al. 2016) is as follows: 


$$
\begin{gathered}
\dot{\varepsilon}_{v p}=\frac{\tilde{\sigma}}{\eta_{4}}=\frac{\sigma}{\eta_{4}(1-D)} \\
D=1-\left(1-\frac{t}{t_{1}}\right)^{\frac{1}{1+\lambda}}
\end{gathered}
$$

where $\tilde{\sigma}$ is the effective stress; $\eta_{4}$ is the viscosity coefficient of the damage viscoplastic body; $D$ is the damage variable; $C$ and $\lambda$ are material parameters; and $t_{1}$ is the time at which the rock undergoes creep failure.

Substituting Eq. (6) into Eq. (5), a one-dimensional creep constitutive equation of the damage viscoplastic body can be obtained as follows:

$$
\dot{\varepsilon}_{v p}=\frac{\sigma}{\eta_{4}}\left(1-\frac{t}{t_{1}}\right)^{-\frac{1}{1+\lambda}}
$$

By integrating Eq. (7) with the initial conditions of $t=0$ and $\varepsilon=0$ and replacing $\sigma$ with $\sigma-\sigma_{s}$, an one-dimensional equation of the damage viscoplastic body can be obtained as follows:

$$
\varepsilon_{v p}=\frac{\sigma-\sigma_{s}}{\eta_{4}} \frac{t_{1}(1+\lambda)}{\lambda}\left[1-(1-D)^{\lambda}\right]
$$

where $\sigma_{s}$ is the long-term strength, which can be obtained from the uniaxial compression creep test.

According to Eqs. (1)-(8), the one-dimensional equation of the damage creep model of layered rock masses can be expressed as following:

$$
\varepsilon= \begin{cases}\frac{\sigma}{E_{1}}+\frac{\sigma}{E_{2}}\left[1-\exp \left(-\frac{E_{2}}{\eta_{2}} t\right)\right] \quad\left(\dot{\varepsilon}(t \rightarrow \infty)=0, \sigma_{0}<\sigma_{s}\right) \\ \frac{\sigma}{E_{1}}+\frac{\sigma}{E_{2}}\left[1-\exp \left(-\frac{E_{2}}{\eta_{2}} t\right)\right]+\frac{\sigma}{\eta_{3}} t \quad\left(\dot{\varepsilon}(t \rightarrow \infty)>0, \sigma_{0}<\sigma_{s}\right) \\ \frac{\sigma}{E_{1}}+\frac{\sigma}{E_{2}}\left[1-\exp \left(-\frac{E_{2}}{\eta_{2}} t\right)\right]+\frac{\sigma}{\eta_{3}} t+ \\ \frac{\sigma-\sigma_{s}}{\eta_{4}} \frac{t_{1}(1+\lambda)}{\lambda}\left[1-\left(1-\frac{t}{t_{1}}\right)^{\frac{\lambda}{1+\lambda}} \quad\left(\sigma_{s} \leq \sigma_{0}\right)\right.\end{cases}
$$

\subsection{Identification and sensitivity analysis of creep parameters}

The nonlinear regression method was used on the uniaxial creep test data of layered phyllite to identify the parameters of the damage creep model of layered rock masses and to obtain the elastic moduli $E_{1}, E_{2}$, viscosity coefficient $\eta_{2}, \eta_{3}, \eta_{4}$, and the value of the material parameter $\lambda$. The time $t_{1}$ for the creep failure of the rock can be obtained from the uniaxial compression creep test. Based on the model parameters corresponding to the layered phyllite creep tests on samples having different bedding angles, the theoretical curve of the model is established with the test time as a consistent independent variable, and the curve is compared with the test data under the same conditions (as shown in Fig. 13). 


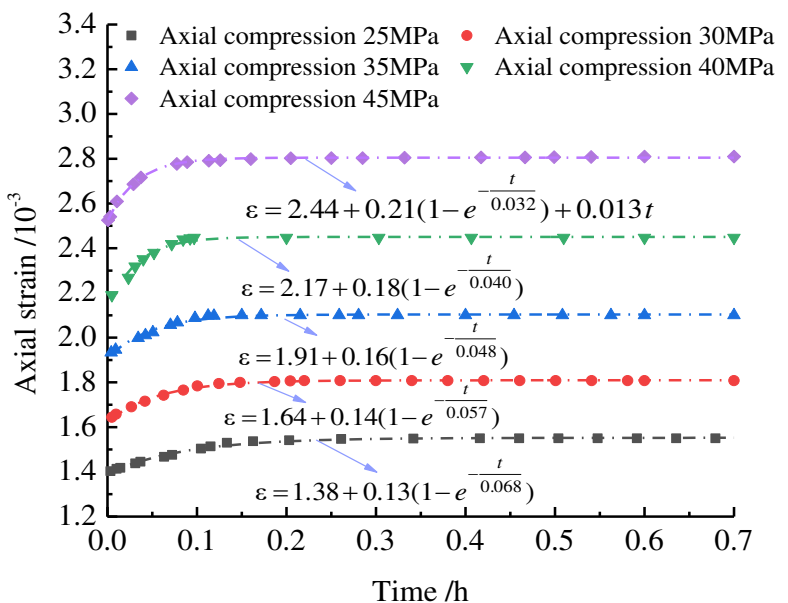

a) Bedding angle of $0^{\circ}$

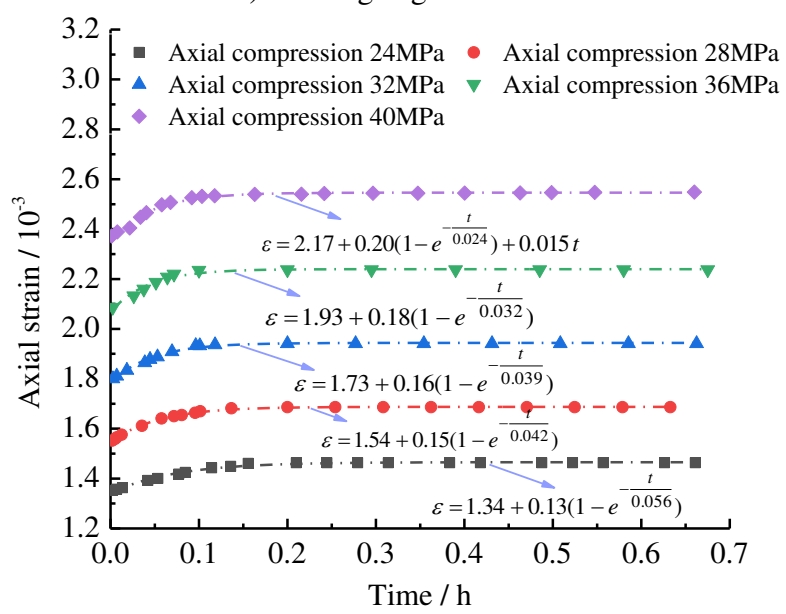

c) Bedding angle of $45^{\circ}$

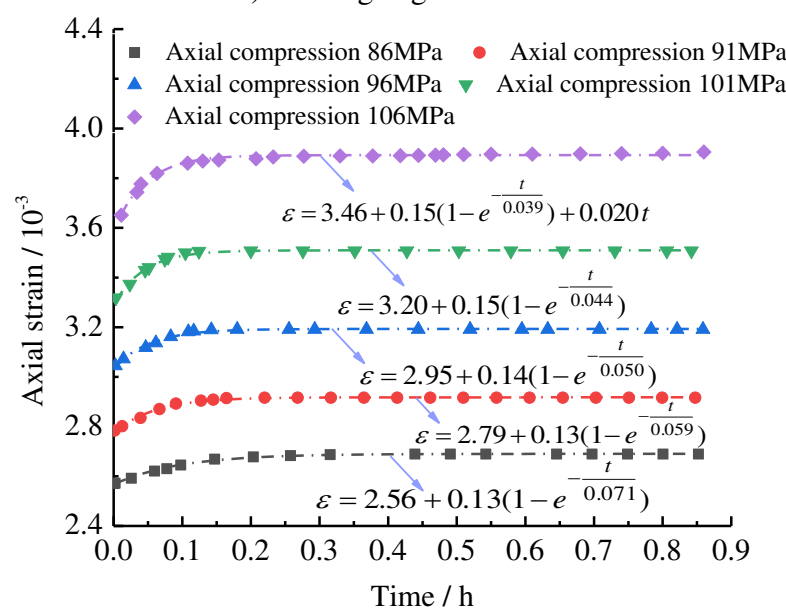

e) Bedding angle of $90^{\circ}$

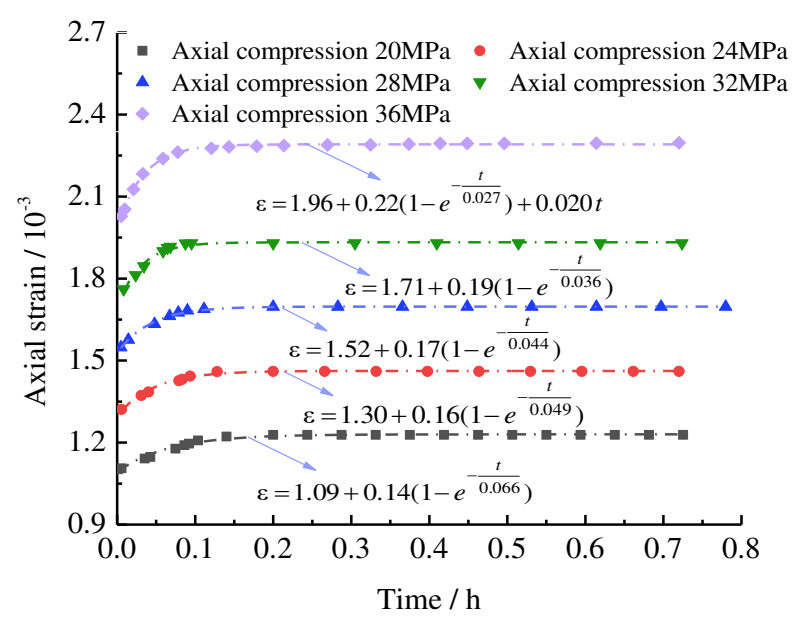

b) Bedding angle of $22.5^{\circ}$

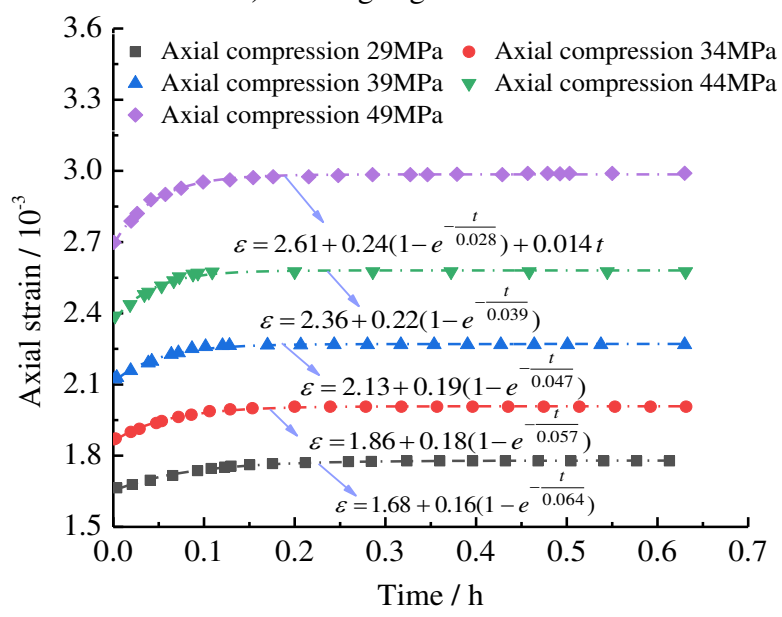

d) Bedding angle of $67.5^{\circ}$

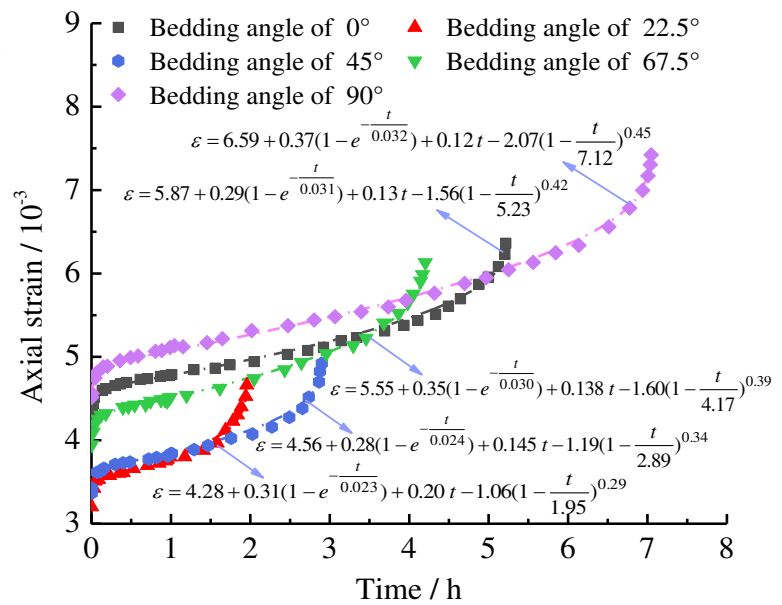

f) The last-stage loading

Fig. 13 Comparison of creep test data and the theoretical curve of layered phyllite samples. a) the first five-stage loading creep curve of the rock sample with a bedding angle of $0^{\circ}$; b) the first five-stage loading creep curve of the rock sample with a bedding angle of $22.5^{\circ}$; c) the first five-stage loading creep curve of the rock sample with a bedding angle of $45^{\circ}$; d) the first five-stage loading creep curve of the rock sample with a bedding angle of $67.5^{\circ}$; e) the first five-stage loading creep curve of the rock sample with a bedding angle of $90^{\circ}$; f) the last-stage loading creep curve of rock samples having bedding angles of $0^{\circ}, 22.5^{\circ}, 45^{\circ}, 67.5^{\circ}$, and $90^{\circ}$.

Table 2 shows the fitting parameters of layered phyllite samples having bedding angles of $0^{\circ}, 22.5^{\circ}$, $45^{\circ}, 67.5^{\circ}$, and $90^{\circ}$ under the creep failure stress. The experimental results show that the elastic modulus 
$E_{2}$ as well as the viscosity coefficients $\eta_{2}$ and $\eta_{3}$ initially decrease and then increase with the increase in bedding angle under low stress levels. Moreover, the changes in the creep parameters causes the cumulative creep deformation and creep time during the steady-state creep stage of the specimens to initially decrease and then increase as the bedding angle changes from $0^{\circ}$ to $90^{\circ}$ (as shown in Fig. 13f), and this is consistent with the experimental results. Under high-stress levels, the directional flow speed of the microelements inside the rock is accelerated, and the internal mechanical properties continue to deteriorate. Compared with the first five stress loading levels, the creep parameters $E_{1}, E_{2}, \eta_{2}$, and $\eta_{3}$ of the rock sample are small in the final loading stage, which demonstrates that the internal viscoelastic and viscoplastic deformations of the rock sample at this time are both large; the rock mass elastic modulus $E_{1}$, $E_{2}$, viscosity coefficient $\eta_{2}, \eta_{3}, \eta_{4}$, and the time required for creep failure $t_{1}$, all decrease first and then increase with increase in the bedding angle (as shown in Fig. 14). The influence of the transverse isotropic characteristics of rocks on the rheological characteristics of layered phyllite cannot be ignored.

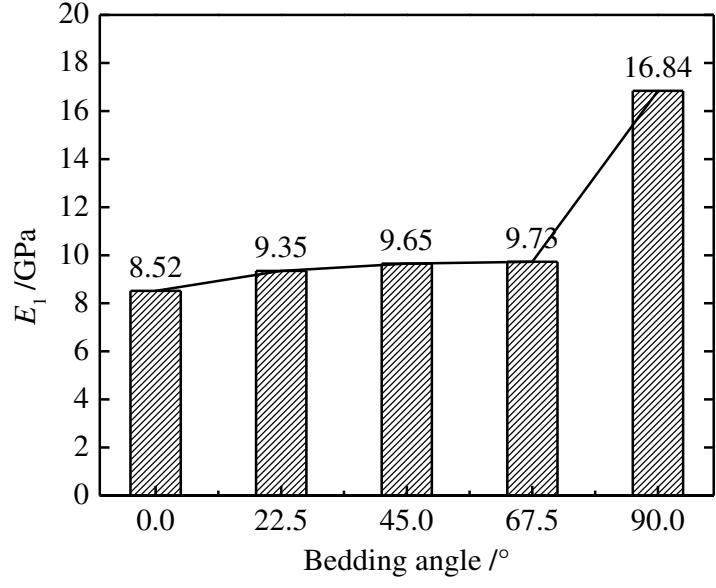

a) Relationship between the bedding angle and elastic

modulus $E_{1}$.

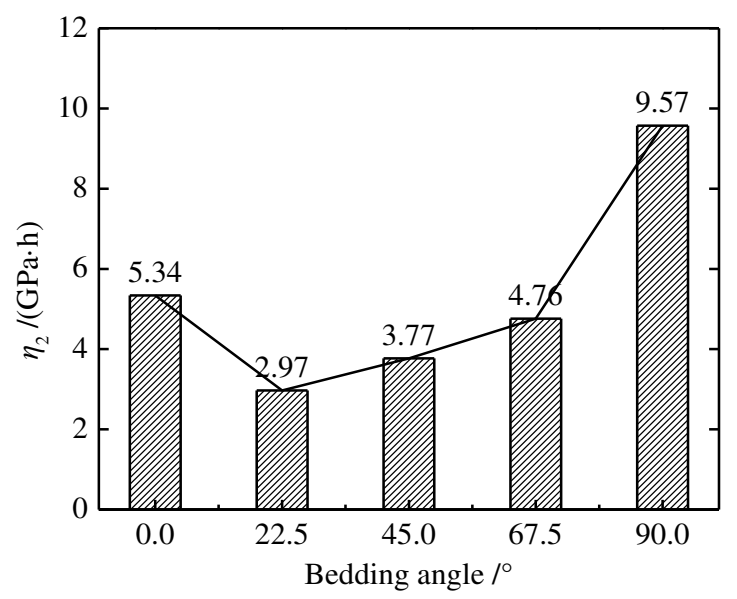

c) Relationship between the bedding angle and viscosity coefficients $\eta_{2}$.

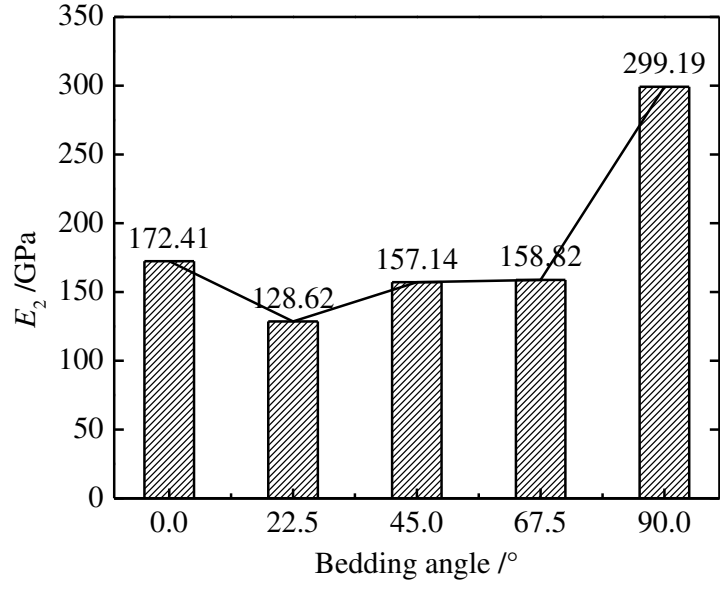

b) Relationship between the bedding angle and elastic

modulus $E_{2}$.

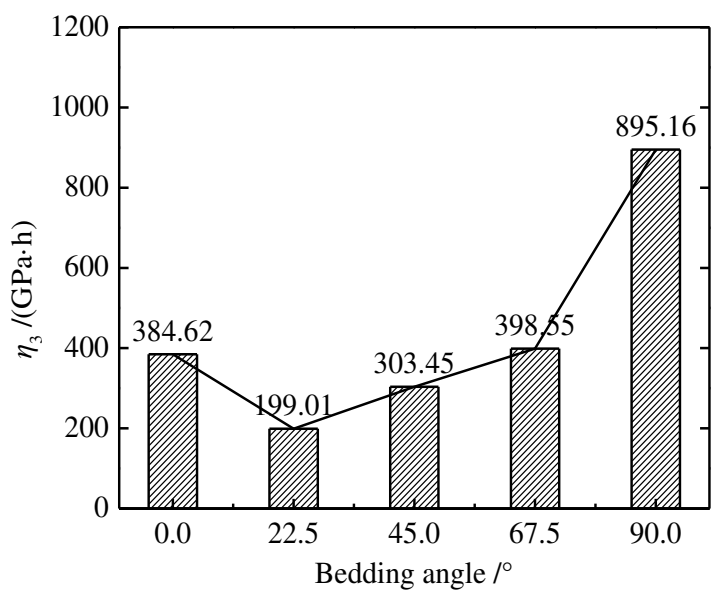

d) Relationship between the bedding angle and viscosity coefficients $\eta_{3}$. 


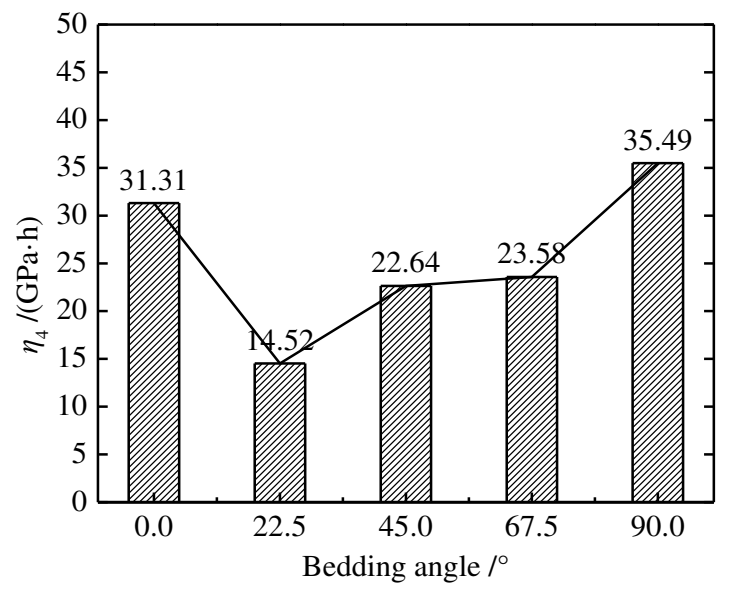

e) Relationship between the bedding angle and viscosity coefficients $\eta_{4}$.

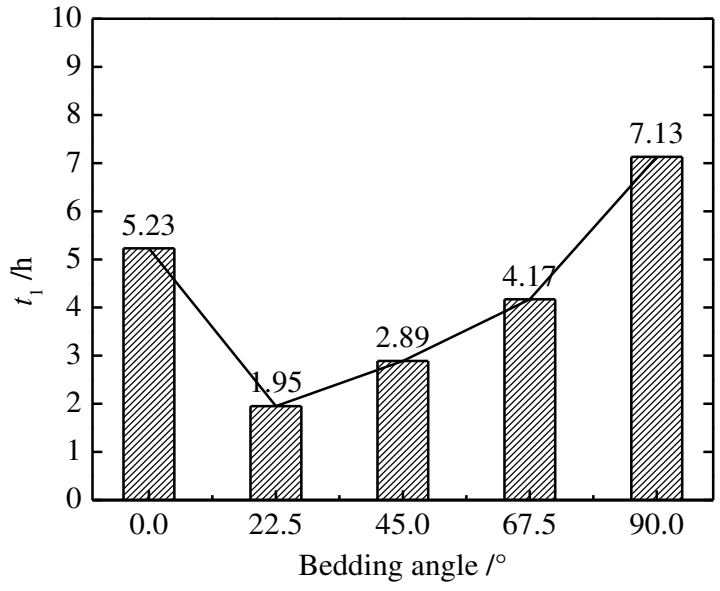

f) Relationship between the bedding angle and creep failure time $t_{1}$.

Fig. 14 Relationship between the bedding angle and creep parameters.

Table 2 Creep parameters of layered phyllite samples having different bedding angles.

\begin{tabular}{|c|c|c|c|c|c|c|c|}
\hline \multirow{2}{*}{$\begin{array}{c}\text { Bedding } \\
\text { angle, } \beta\left(^{\circ}\right)\end{array}$} & \multirow{2}{*}{$\begin{array}{l}\text { Axial compression } \\
(\mathrm{MPa})\end{array}$} & \multicolumn{6}{|c|}{ Creep parameters } \\
\hline & & $E_{1}(\mathrm{GPa})$ & $E_{2}(\mathrm{GPa})$ & $\eta_{2}(\mathrm{GPa} \cdot \mathrm{h})$ & $\eta_{3}(\mathrm{GPa} \cdot \mathrm{h})$ & $\eta_{4}(\mathrm{GPa} \cdot \mathrm{h})$ & $t_{1}(\mathrm{~h})$ \\
\hline \multirow{6}{*}{0} & 25 & 18.06 & 192.30 & 13.08 & - & - & - \\
\hline & 30 & 18.29 & 214.29 & 12.21 & - & - & - \\
\hline & 35 & 18.32 & 218.75 & 10.50 & - & - & - \\
\hline & 40 & 18.43 & 222.22 & 8.89 & - & - & - \\
\hline & 45 & 18.52 & 224.17 & 7.19 & 3461.54 & - & - \\
\hline & 50 & 8.52 & 172.41 & 5.34 & 384.62 & 31.31 & 5.23 \\
\hline \multirow{6}{*}{22.5} & 20 & 18.39 & 142.86 & 9.43 & - & - & - \\
\hline & 24 & 18.46 & 150.00 & 7.35 & - & - & - \\
\hline & 28 & 18.54 & 164.71 & 7.24 & - & - & - \\
\hline & 32 & 18.60 & 168.42 & 6.06 & - & - & - \\
\hline & 36 & 18.62 & 171.42 & 4.63 & 1800.05 & - & - \\
\hline & 40 & 9.35 & 128.62 & 2.97 & 199.01 & 14.52 & 1.95 \\
\hline \multirow{6}{*}{45} & 24 & 17.91 & 179.10 & 10.03 & - & - & - \\
\hline & 28 & 18.18 & 186.66 & 7.84 & - & - & - \\
\hline & 32 & 18.49 & 191.62 & 7.47 & - & - & - \\
\hline & 36 & 18.65 & 200.02 & 6.40 & - & - & - \\
\hline & 40 & 18.96 & 203.42 & 4.88 & 2758.62 & - & - \\
\hline & 44 & 9.65 & 157.14 & 3.77 & 303.45 & 22.64 & 2.89 \\
\hline \multirow{6}{*}{67.5} & 29 & 17.26 & 181.25 & 11.60 & - & - & - \\
\hline & 34 & 18.28 & 188.89 & 10.75 & - & - & - \\
\hline & 39 & 18.31 & 198.98 & 9.35 & - & - & - \\
\hline & 44 & 18.64 & 209.53 & 8.17 & - & - & - \\
\hline & 49 & 18.77 & 213.04 & 5.96 & 3450.70 & - & - \\
\hline & 54 & 9.73 & 158.82 & 4.76 & 398.55 & 23.58 & 4.17 \\
\hline
\end{tabular}




\begin{tabular}{cccccccc}
\hline & 86 & 32.45 & 661.54 & 46.97 & - & - & - \\
& 91 & 32.61 & 684.21 & 40.37 & - & - & - \\
90 & 96 & 32.64 & 685.71 & 34.28 & - & - & - \\
& 101 & 32.65 & 687.07 & 30.23 & - & - & - \\
& 106 & 32.77 & 706.66 & 27.55 & 5273.63 & - & - \\
& 111 & 16.84 & 299.19 & 9.57 & 895.16 & 35.49 & 7.13 \\
\hline
\end{tabular}

\section{Discussion}

The long-term load damage parameters $D$ and $\lambda$ were introduced into the damage creep model of layered rock masses, and these parameters play a key role in describing the damage characteristics of layered rock masses during the accelerated creep stage. Therefore, this section focuses on the effect of the long-term load damage parameters on the transversely isotropic creep characteristics and the damage mechanism of rock samples having different bedding angles during the accelerated creep stage.

Fig. 15 shows the variation of damage variable with time for rock samples having different bedding angles during the accelerated creep stage. As the long-term load damage parameter $\lambda$ of the specimens decreases, the nonlinear change trend of the curve becomes more significant and the shorter the time required for the damage variable $D$ of the rock sample to reach 1 . These observations indicate that the damage creep model can describe well the accelerated creep characteristics of layered rock masses.

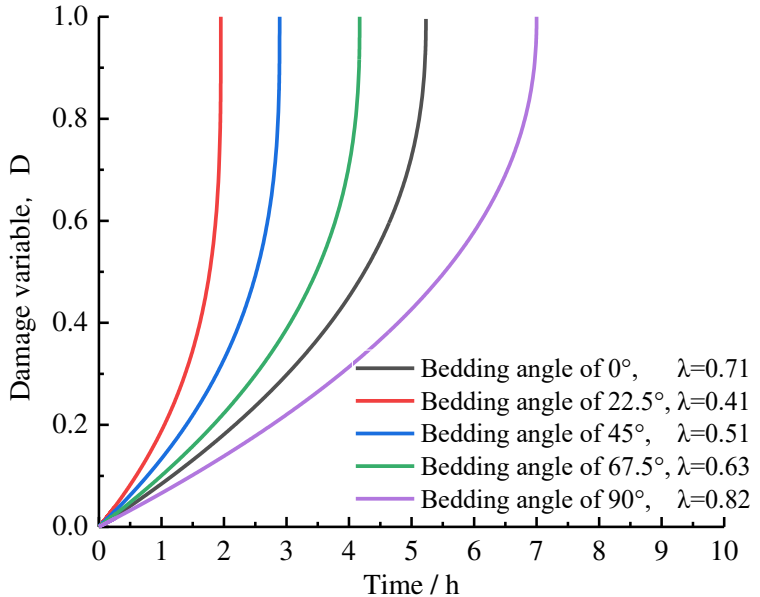

Fig. 15 Damage variable vs. time for rock samples having different bedding angles during the accelerated creep stage.

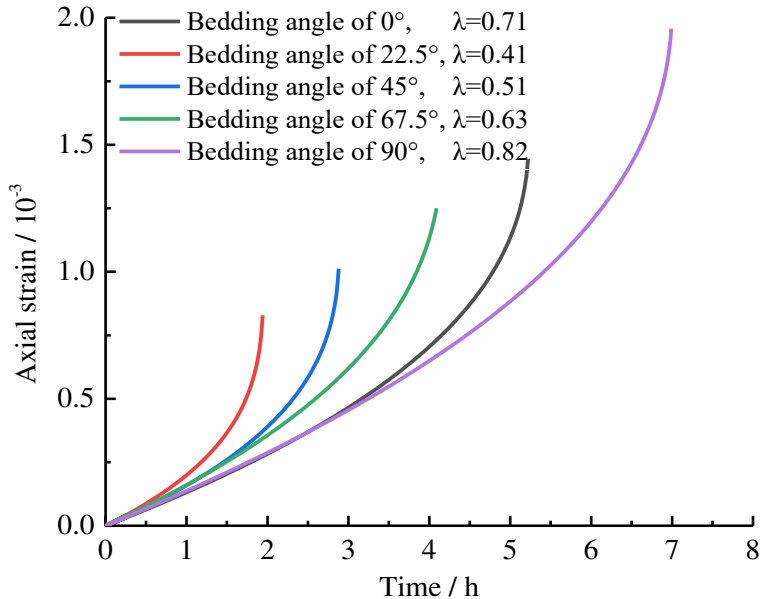

Fig. 16 Creep curves of rock samples having different bedding angles during the accelerated creep stage.

Fig. 16 shows the creep curves of rock samples having different bedding angles during the accelerated creep stage. When the bedding angle is $22.5^{\circ}, 45^{\circ}$, and $67.5^{\circ}$, the creep deformation rate of the rock sample increases, the curve becomes steeper, and the long-term load damage parameter $\lambda$ of the rock sample is $0.41,0.51$, and 0.63 , respectively. When the bedding angles are $0^{\circ}$ and $90^{\circ}$, the accelerated creep stage of the rock sample is longer, the creep deformation rate is smaller, the curve is smoother, and the long-term 
load damage parameters $\lambda$ of the rock sample are 0.71 and 0.82 , respectively. Results show that as the bedding angle changes from $0^{\circ}$ to $90^{\circ}$, the long-term load damage parameter $\lambda$ of the rock sample first decreases and then increases. In addition, the time required for the accumulation of microscopic cracks in the corresponding rock sample during the accelerated creep stage to the generation of the macroscopic section first decreases and then increases. The damage creep model effectively reflects and predicts the transversely isotropic creep damage mechanism of layered rock masses.

\section{Summary and conclusions}

To develop a comprehensive understanding of the creep characteristics and damage mechanism of layered rock masses, a series of uniaxial compression creep experiments were conducted on layered phyllite samples having bedding angles of $0^{\circ}, 22.5^{\circ}, 45^{\circ}, 67.5^{\circ}$, and $90^{\circ}$.

The laboratory test results show that the creep deformation of layered phyllite can be classified into four stages: the instantaneous elastic deformation stage, the deceleration creep stage, the steady-state creep stage, and the accelerated creep stage. The creep characteristics of layered phyllites are significantly affected by the weak bedding planes; specifically, the cumulative creep deformation and the creep time during the steady-state creep stage of the specimens initially decrease and then increase as the bedding angle changes from $0^{\circ}$ to $90^{\circ}$, thereby, corresponding to the initial increase and subsequent decrease in creep rate during the deceleration creep stage.

Based on the existing viscoelastic-plastic damage creep model, the creep parameters were identified, and the variation trend of creep parameters was studied. At low-stress levels, the elastic modulus $E_{2}$ as well as the viscosity coefficients $\eta_{2}$ and $\eta_{3}$ all first decrease and then increase as the bedding angle changes from $0^{\circ}$ to $90^{\circ}$. Under high-stress levels, the elastic moduli $E_{1}, E_{2}$, viscosity coefficient $\eta_{2}, \eta_{3}, \eta_{4}$, and the time required for creep failure $t_{1}$ all first decrease and then increase with increase in the bedding angle.

\section{Acknowledgements}

This study was financially supported by the National Natural Science Foundation of China (Grant Nos. 51978668 and 51578550), the Research Foundation of Education Bureau of Hunan Province (Grant No. 19K100), and the Innovation Project of Guangxi Graduate Education (Grant No. YCSW2021021).

\section{References}

Cao P, Wen YD, Wang YX, Yuan HP, Yuan BX (2016) Study on nonlinear damage creep constitutive model for high-stress soft rock. Environmental Earth Sciences 75(10): 900, DOI: 10.1007/s12665-016-5699-x 
Chen DF, Xu DP, Ren GF, Jiang Q, Liu GF, Wan LP, Li N (2019) Simulation of cross-correlated non-Gaussian random fields for layered rock mass mechanical parameters. Computers and Geotechnics 112: 104-119, DOI: 10.1016/j.compgeo.2019.04.012

Chen L, Wang CP, Liu JF, Li Y, Liu J, Wang J (2017) Effects of temperature and stress on the time-dependent behavior of Beishan granite. International Journal of Rock Mechanics and Mining Sciences 93: 316-323, DOI: 10.1016/j.ijrmms.2016.11.007

Chen ZQ, He C, Xu GW, MA GY, Wu D (2019) A case study on the asymmetric deformation characteristics and mechanical behavior of deep-buried tunnel in phyllite. Rock Mechanics and Rock Engineering 52: 4527-4545, DOI: $10.1007 / \mathrm{s} 00603-019-01836-2$

Fu HL, Zhang JB, Huang Z, Shi Y, Chen W (2018) A statistical model for predicting the triaxial compressive strength of transversely isotropic rocks subjected to freeze-thaw cycling. Cold Regions Science and Technology 145: 237-248, DOI: $10.1016 /$ j.coldregions.2017.11.003

Hadiseh M, Ajalloeian R (2018) Mechanical behavior of salt rock under uniaxial compression and creep tests. International Journal of Rock Mechanics and Mining Sciences 110: 19-27, DOI: 10.1016/j.ijrmms.2018.07.006

Hu SC, Tan YL, Zhou H, Guo WY, Hu DW, Meng FZ, Liu ZG (2017) Impact of bedding planes on mechanical properties of sandstone. Rock Mechanics and Rock Engineering 50(8): 2243-2251, DOI: 10.1007/s00603-017-1239-6

ISRM (2007) The complete ISRM suggested methods for rock characterization, testing and monitoring: 1974-2006. In: Ulusay, R., Hudson, J.A. (Eds.), Suggested Methods Prepared by the Commission on Testing Methods. International Society for Rock Mechanics, Compilation Arranged by the ISRM Turkish National Group, Ankara, Turkey, pp. 628.

Kachanov M (1992) Effective elastic properties of cracked solids: critical review of basic concepts. Applied Mechanics Reviews 45(8): 304-335, DOI: 10.1115/1.3119761

Lee YK, Pietruszczak S (2015) Tensile failure criterion for transversely isotropic rocks. International Journal of Rock Mechanics and Mining Sciences 79: 205-215, DOI: 10.1016/j.ijrmms.2015.08.019

Li XC, Yang CL, Ren T, Nie BS, Zhao CH, Liu SW, Jiang T (2017) Creep behaviour and constitutive model of coal filled with gas. International Journal of Mining Science and Technology 27: 847-851, DOI: 10.1016/j.ijmst.2017.07.017

Liu HZ, Xie HQ, He JD, Xiao ML, Zhuo L (2017) Nonlinear creep damage constitutive model for soft rocks. Mechanics of Time-dependent Materials 21(1): 73-96, DOI: 10.1007/s11043-016-9319-7

Nadimi S, Shahriar K, Sharifzadeh M, Moarefvand P (2011) Triaxial creep tests and back analysis of time-dependent behavior of Siah Bisheh cavern by 3-Dimensional Distinct Element Method. Tunnelling and Underground Space Technology 26: 155-162, DOI: 10.1016/j.tust.2010.09.002

Reza Taheri S, Pak A, Shad S, Mehrgini B, Razifar M (2020) Investigation of rock salt layer creep and its effects on casing collapse. International Journal of Mining Science and Technology 30: 357-365, DOI: 10.1016/j.ijmst.2020.02.001

Shen PW, Tang HM, Zhang BC, Ning YB, He C (2021) Investigation on the fracture and mechanical behaviors of simulated transversely isotropic rock made of two interbedded materials. Engineering Geology 286: 106058, DOI: 10.1016/j. enggeo.2021.106058

Tien YM, Kuo MC, Juang CH (2006) An experimental investigation of the failure mechanism of simulated transversely isotropic rocks. International Journal of Rock Mechanics and Mining Sciences 43: 1163-1181, DOI: 10.1016/j.ijrmms.2006.03.011 
Wang JB, Zhang Q, Song ZP, Zhang YW (2021) Experimental study on creep properties of salt rock under long-period cyclic loading. International Journal of Fatigue 143: 106009, DOI: 10.1016/j.ijfatigue.2020.106009

Wu F, Zhang H, Zou QL, Li CB, Chen J, Gao RB (2020) Viscoelastic-plastic damage creep model for salt rock based on fractional derivative theory. Mechanics of Materials 150: 103600, DOI: 10.1016/j.mechmat.2020.103600

Xie SY, Shao JF, Xu WY (2011) Influences of chemical degradation on mechanical behaviour of a limestone. International Journal of Rock Mechanics and Mining Sciences 48: 741-747, DOI: 10.1016/j.ijrmms.2011.04.015

Xu GW, He C, Su Ang, Chen ZQ (2018) Experimental investigation of the anisotropic mechanical behavior of phyllite under triaxial compression. International Journal of Rock Mechanics and Mining Sciences 104: 100-112, DOI: 10.1016/j.ijrmms.2018.02.017

Xu GW, He C, Chen ZQ, Yang QH (2020) Transversely isotropic creep behavior of phyllite and its influence on the long-term safety of the secondary lining of tunnels. Engineering Geology 278: 105834, DOI: 10.1016/j. enggeo.2020.105834

Yang WD, Zhang QY, Li SC, Wang SG (2014) Time-dependent behavior of diabase and a nonlinear creep model. Rock Mechanics and Rock Engineering 47: 1211-1224, DOI: 10.1007/s00603-013-0478-4

Yang SQ, Xu P, Ranjith PG (2015) Damage model of coal under creep and triaxial compression. International Journal of Rock Mechanics and Mining Sciences 80: 337-345, DOI: 10.1016/j.jirmms.2015.10.006

Yang SQ, Yin PF, Huang YH, Cheng JL (2021) Strength, deformability and X-ray micro-CT observations of transversely isotropic composite rock under different confining pressures. Engineering Fracture Mechanics 241: 107389, DOI: 10.1016/j.engfracmech.2019.04.030

Zhang JB, Fu HL, Huang Z, Wu YM, Chen W, Shi Y (2019) Experimental study on the tensile strength and failure characteristics of transversely isotropic rocks after freeze-thaw cycles. Cold Regions Science and Technology 163: 68-77, DOI: 10.1016/j.coldregions.2019.04.006

Zhao YL, Cao P, Wang WJ, Wan W, Liu YK (2009) Viscoelasto-plastic rheological experiment under circular increment step load and unload and nonlinear creep model of soft rocks. Joumal of Central South University of Technology 16: 0488-0494, DOI: $10.1007 / \mathrm{s} 11771-009-0082-7$

Zhao YL, Wang YX, Wang WJ, Wan W, Tang JZ (2017) Modeling of non-linear rheological behavior of hard rock using triaxial rheological experiment. International Journal of Rock Mechanics and Mining Sciences 93: 66-75, DOI: 10.1016/j.ijrmms.2017.01.004

Zhou HW, Wang CP, Han BB, Duan ZQ (2011) A creep constitutive model for salt rock based on fractional derivatives. International Journal of Rock Mechanics and Mining Sciences 48(1): 116-121, DOI: 10.1016/j.ijrmms.2010.11.004 